\title{
Intermédialités
}

Histoire et théorie des arts, des lettres et des techniques

Intermediality

History and Theory of the Arts, Literature and Technologies

\section{Dripping Ground Zero}

\section{Alain Escalle}

Numéro 1, printemps 2003

Naître

URI : https://id.erudit.org/iderudit/1005452ar

DOI : https://doi.org/10.7202/1005452ar

Aller au sommaire du numéro

Éditeur(s)

Centre de recherche sur l'intermédialité

ISSN

1920-3136 (numérique)

Découvrir la revue

Citer ce document

Escalle, A. (2003). Dripping Ground Zero. Intermédialités / Intermediality, (1),

170-175. https://doi.org/10.7202/1005452ar d'utilisation que vous pouvez consulter en ligne.

https://apropos.erudit.org/fr/usagers/politique-dutilisation/ 

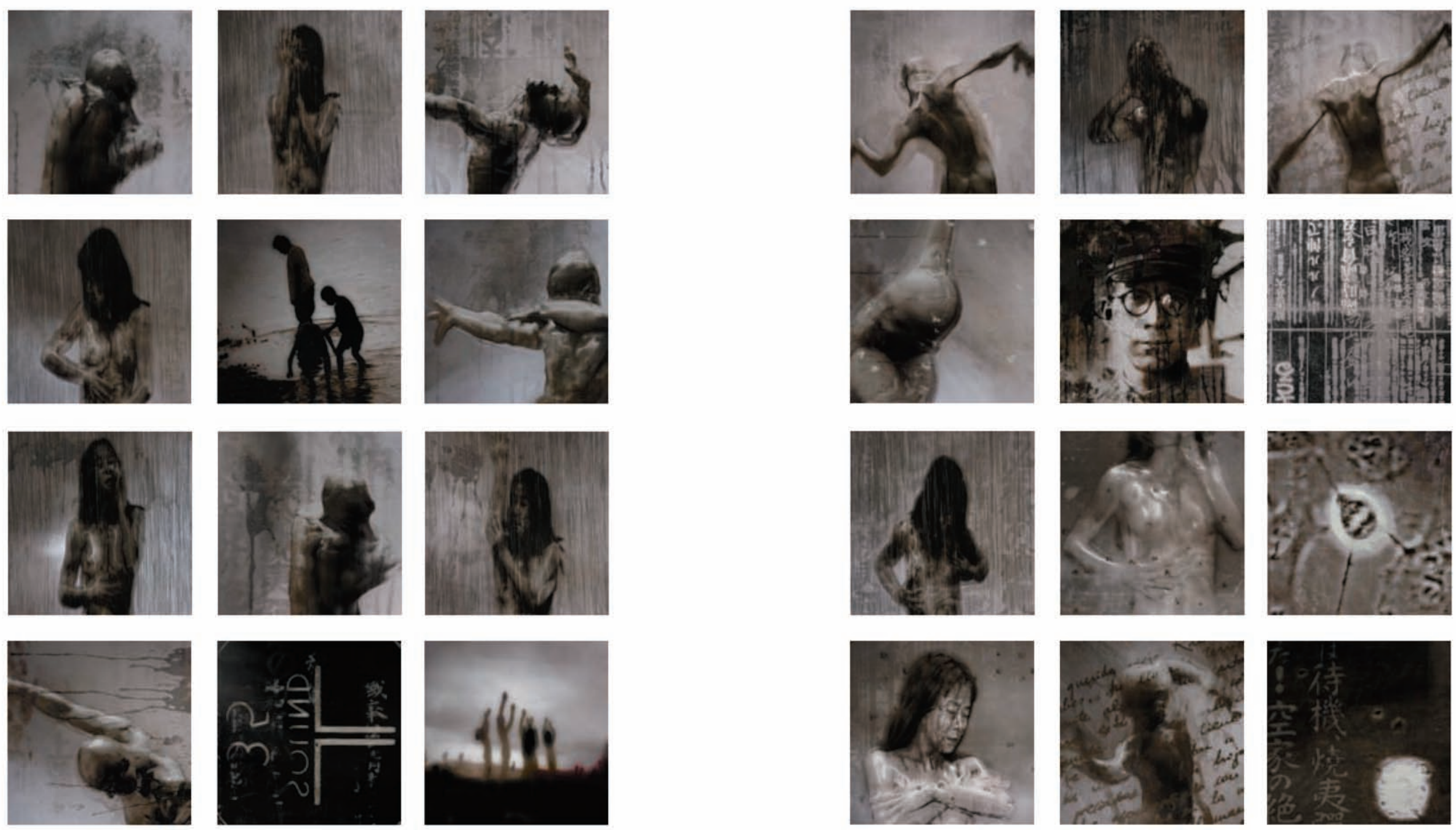

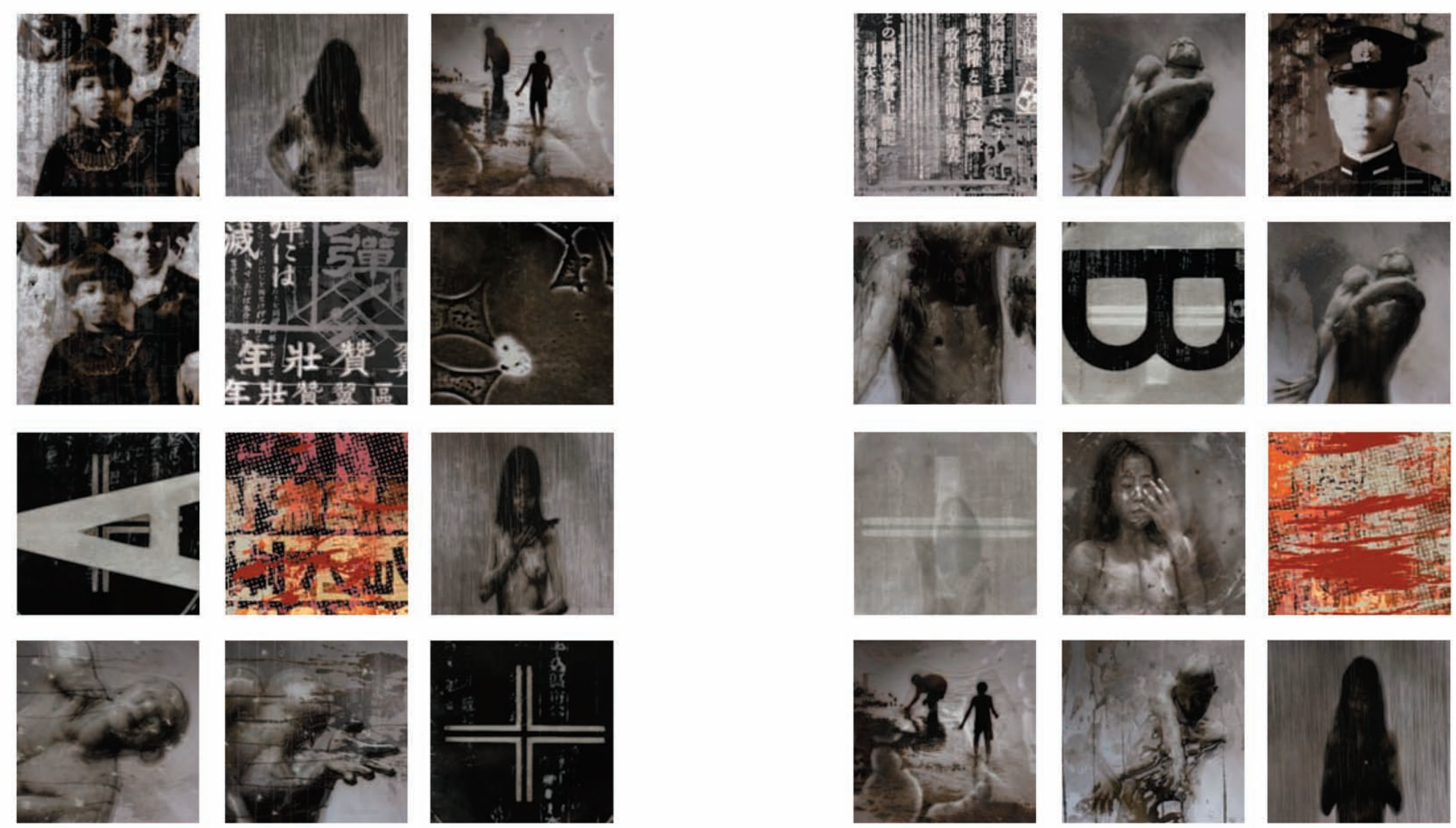

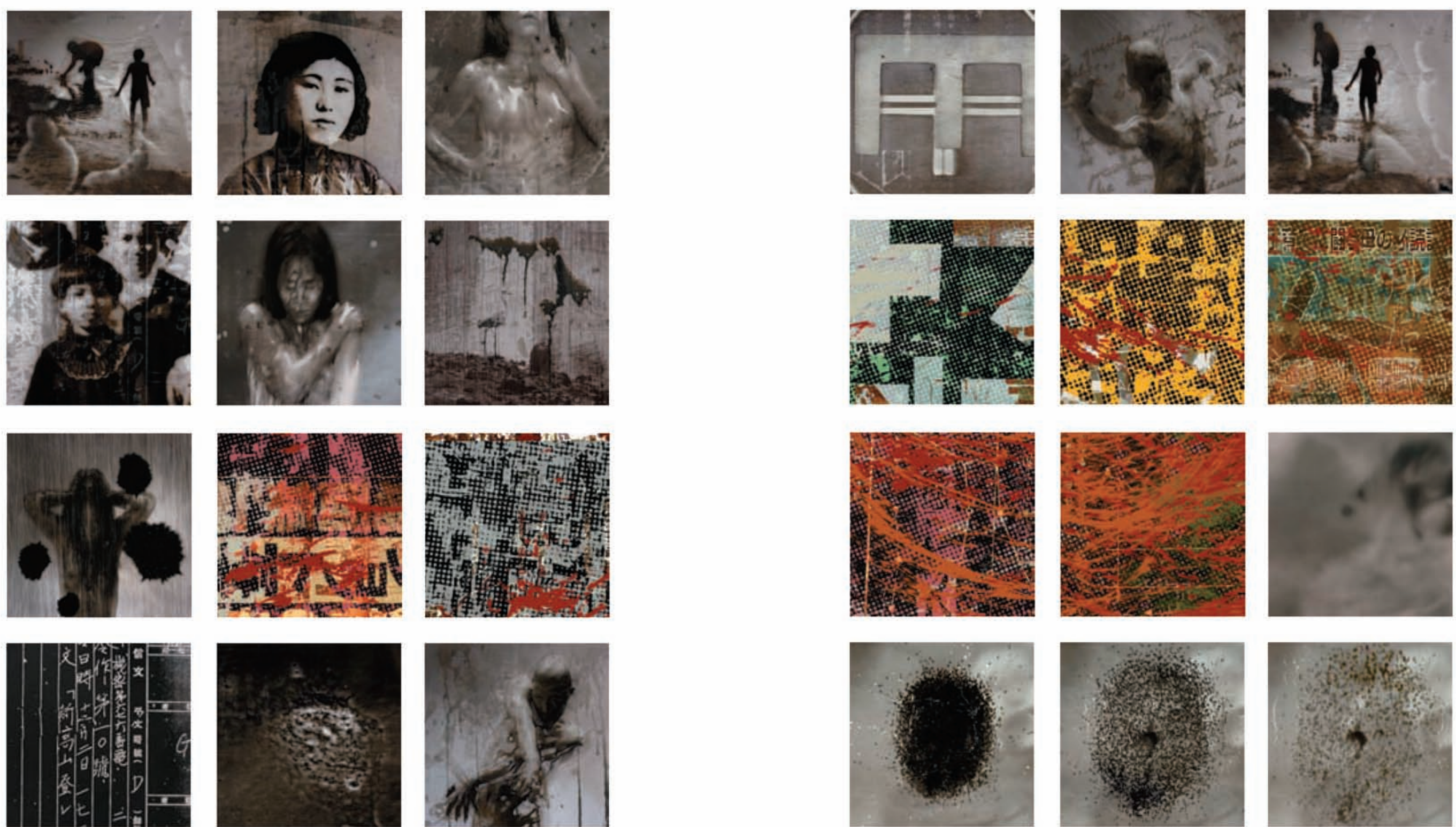